\title{
Aortic Root Calcification: A Possible Imaging Biomarker of Coronary Atherosclerosis
}

\author{
Hussein Nafakhi ${ }^{a}$ Hasan A. Al-Nafakh ${ }^{b}$ Abdulameer A. Al-Mosawi ${ }^{\text {b }}$ \\ a Internal Medicine Department, AL-Sader Teaching Hospital, Medicine College, Kufa \\ University, and ${ }^{\mathrm{b}}$ Radiology Department, Medicine College, Kufa University, Najaf, Iraq
}

\section{Key Words}

Coronary artery calcification · Coronary computed tomographic angiography

\section{Abstract}

It has been reported that coronary atherosclerosis risk assessment using coronary artery calcium and thoracic aorta calcium quantification may improve risk stratification as it can lead to the reclassification of persons at increased risk. The aortic root has been characterized by its close anatomical proximity to the ostial origins of the right and left coronary arteries, and it can be evaluated using multi-detector computed tomography without additional radiation exposure and the use of contrast. The correlations between aortic root calcification and coronary atherosclerotic markers as well as cardiac risk factors have been analyzed.

Multi-detector computed tomography (MDCT) has become the preferred imaging modality for coronary artery disease (CAD) and coronary artery calcification (CAC). Assessment with MDCT provides incremental prognostic values beyond those of traditional cardiac risk factors as well as scores for cardiovascular disease morbidity and mortality reported in several large follow-up studies, and it may help in the reclassification of patients at increased risk [1-4].

Screening asymptomatic persons for the prevention of cardiovascular events remains a major challenge $[4,5]$. Conventional cardiovascular risk factors such as age, gender, lipids, 


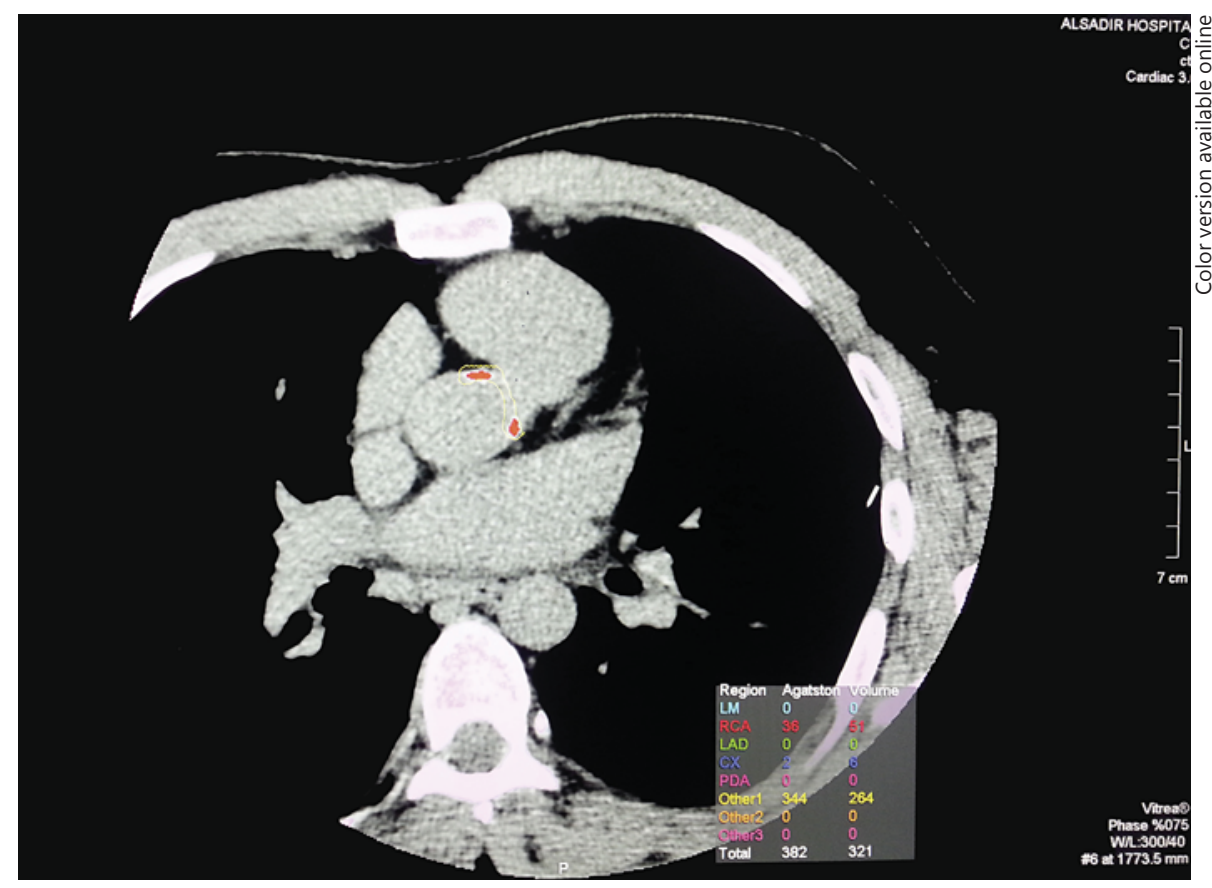

Fig. 1. Aortic root calcium score measurement by MDCT.

hypertension, and smoking are traditionally employed to assess the individual risk status and to guide drug prescription in order to prevent cardiovascular events $[6,7]$.

Although the established primary prevention risk-scoring methods based on conventional risk factors as predictors of cardiovascular events using equations derived from large prospective cohort studies are important, further fine-tuning of cardiovascular risk assessment remains important as $25 \%$ of individuals with a low estimated risk may experience cardiac events $[4,5]$. Therefore, extended or modified risk assessment using coronary artery calcium and thoracic aorta calcium quantification may improve risk stratification as it can lead to the reclassification of persons at an increased risk, and the implementation of these CAC and aorta calcium scores may allow further fine-tuning of cardiovascular risk prediction in specific subpopulations [8-11].

Aortic calcification is an actively regulated process that leads to increased vascular stiffness and cardiovascular morbidity and mortality compared to similar patients without calcification, and it has been suggested that the presence of aortic calcification can be regarded as an additional marker for atherosclerotic burden and cardiovascular events $[12,13]$.

Unlike concerning coronary calcification, relatively little is known about the importance of aortic root calcification (ARC) and the association between ARC (as a part of the thoracic aorta) and coronary atherosclerosis burden and calcification, because the evaluation of the aortic root or of thoracic aorta calcification is not a standard part of the routine cardiovascular workup [14]. The aortic root has been characterized by its close anatomical proximity to the cardiac chambers and the ostial origins of the right and left coronary arteries. It can be evaluated using MDCT without additional radiation exposure and the use of contrast [14]. Moreover, aortic root lesions and calcification can be easily evaluated and followed using transthoracic echocardiography [14].

Interestingly, previous follow-up studies have reported that the earliest accelerated calcification event may occur in the aortic root and in the proximal parts of the coronary 
Fig. 2. A significant correlation was observed between ARC and total CAC.

Fig. 3. A significant correlation was observed between ARC and age $\geq 65$ years.
Nafakhi et al.: Aortic Root Calcification: A Possible Imaging Biomarker of Coronary Atherosclerosis
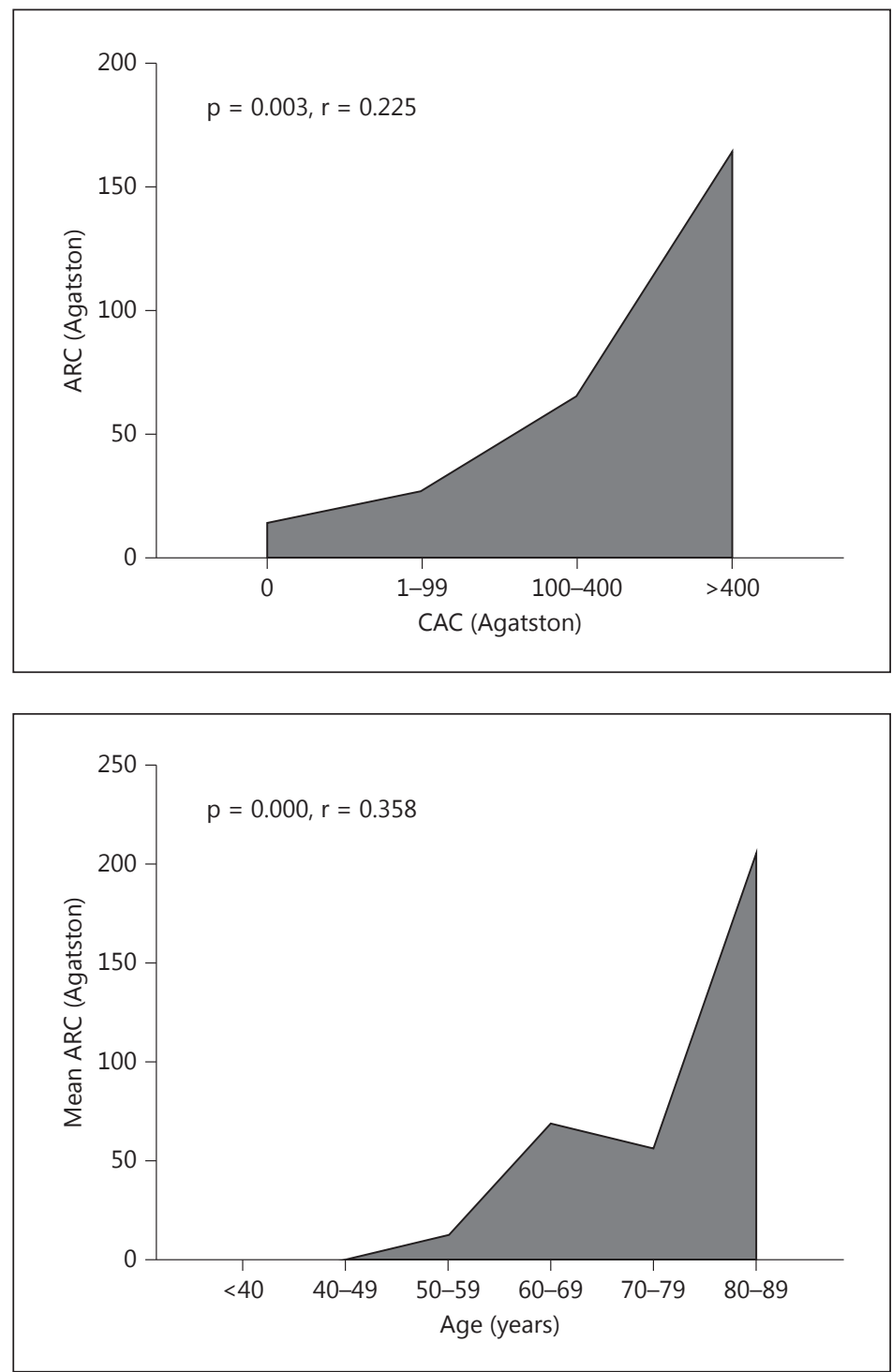

vessels, which may reflect the natural history of coronary atherosclerosis [15, 16]. Additionally, aortic calcification may presage the development of symptomatic CAD, particularly in patients with hyperlipidemia [17].

Correlations between ARC quantified using MDCT and coronary atherosclerotic markers (CAC, calcified plaques, and luminal stenosis) were investigated in 175 consecutive patients with an intermediate pretest probability of ischemic heart disease [14]. The aortic root was defined as the part of the aorta lying within $3 \mathrm{~cm}$ of the caudal aspect of the aortic annulus containing the sinuses of Valsalva and the sinotubular junction (fig. 1). The total calcium score of the aortic root was calculated using the Agatston method and the corresponding definition. Areas in the aortic root with an attenuation $>130$ Hounsfield units and an area $>1 \mathrm{~mm}^{2}$ were considered to be calcified lesions [14].

A significant correlation was observed between ARC and total CAC $(r=0.225, p=0.003$; fig. 2). Also, a strong correlation was observed between ARC and the number of coronary stenotic vessels $(r=0.67, p<0.001)$. 
Fig. 4. A significant correlation was observed between ARC and male sex in patients with a CAC score $>0$.
Nafakhi et al.: Aortic Root Calcification: A Possible Imaging Biomarker of Coronary Atherosclerosis

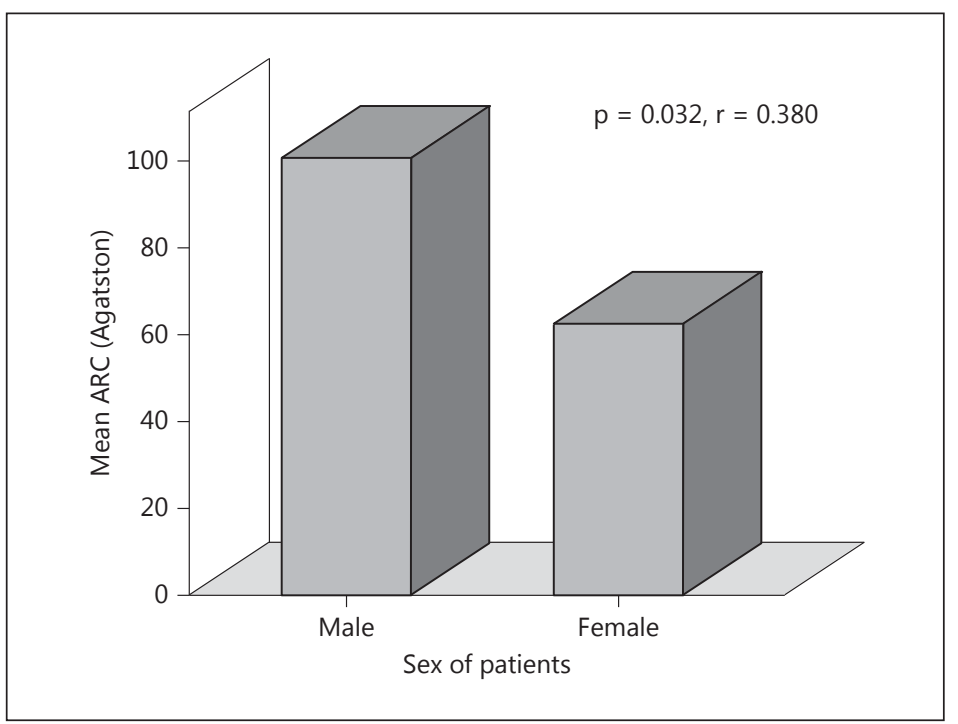

A further analysis was performed to investigate the relationship between clinical cardiac risk factors (hypertension, smoking, diabetes mellitus, hyperlipidemia, family history of premature coronary disease, obesity, male sex, and older age) and ARC in 69 patients with a CAC score $>0$ using MDCT.

A significant correlation was observed between ARC and age $\geq 65$ years $(r=0.353, p=0.047$; fig. 3 ) and between ARC and male sex ( $r=0.380, p=0.032$; fig. 4). These correlations persisted even after multivariate adjustment for other cardiac risk factors. There were no significant correlations between ARC and other cardiac risk factors, and the only significant between-group difference in the distribution of cardiac risk factors was found in patient age [18].

In conclusion, these results suggest that ARC can be used as an additional imaging marker for the assessment of coronary atherosclerosis and may have a complementary role with CAC in the detection of CAD. Further studies using larger population sizes and including a followup are needed to establish a causal relationship between cardiac risk factors and ARC. This will facilitate better risk stratification for cardiovascular diseases and help physicians to initiate appropriate interventions earlier, which in turn may arrest the progression of ARC and prevent irreversible changes in arterial hemodynamics.

\section{Disclosure Statement}

The authors have no conflicts of interest to disclose.

\section{References}

1 Feuchtner G: Imaging of cardiac valves by computed tomography. Scientifica (Cairo) 2013;2013:270579.

2 Nasir K, Rubin J, Blaha MJ, Shaw LJ, Blankstein R, Rivera JJ, Khan AN, Berman D, Raggi P, Callister T, Rumberger JA, Min J, Jones SR, Blumenthal RS, Budoff MJ: Interplay of coronary artery calcification and traditional risk factors for the prediction of all-cause mortality in asymptomatic individuals. Circ Cardiovasc Imaging 2012;5: 467-473.

3 Silverman MG, Blaha MJ, Krumholz HM, Budoff MJ, Blankstein R, Sibley CT, Agatston A, Blumenthal RS, Nasir $\mathrm{K}$ : Impact of coronary artery calcium on coronary heart disease events in individuals at the extremes of traditional risk factor burden: the Multi-Ethnic Study of Atherosclerosis. Eur Heart J 2014;35:2232-2241. 
Nafakhi et al:: Aortic Root Calcification: A Possible Imaging Biomarker of Coronary Atherosclerosis

4 Hartmann M, von Birgelen C: Is there a role for thoracic aortic calcium to fine-tune cardiovascular risk prediction? Int J Cardiovasc Imaging 2013;29:217-219.

5 Erbel R, Möhlenkamp S, Moebus S, Schmermund A, Lehmann N, Stang A, Dragano N, Grönemeyer D, Seibel R, Kälsch H, Bröcker-Preuss M, Mann K, Siegrist J, Jöckel KH; Heinz Nixdorf Recall Study Investigative Group: Coronary risk stratification, discrimination, and reclassification improvement based on quantification of subclinical coronary atherosclerosis: the Heinz Nixdorf Recall Study. J Am Coll Cardiol 2010;56:1397-1406.

6 Assmann G, Cullen P, Schulte H: Simple scoring scheme for calculating the risk of acute coronary events based on the 10-year follow-up of the prospective cardiovascular Münster (PROCAM) study. Circulation 2002;105: 310-315.

7 Conroy RM, Pyörälä K, Fitzgerald AP, et al; SCORE project group: Estimation of ten-year risk of fatal cardiovascular disease in Europe: the SCORE project. Eur Heart J 2003;24:987-1003.

8 Polonsky TS, McClelland RL, Jorgensen NW, Bild DE, Burke GL, Guerci AD, Greenland P: Coronary artery calcium score and risk classification for coronary heart disease prediction. JAMA 2010;303:1610-1616.

9 Greenland P, LaBree L, Azen SP, Doherty TM, Detrano RC: Coronary artery calcium score combined with Framingham score for risk prediction in asymptomatic individuals. JAMA 2004;291:210-215.

10 Elias-Smale SE, Proença RV, Koller MT, Kavousi M, van Rooij FJ, Hunink MG, Steyerberg EW, Hofman A, Oudkerk M, Witteman JC: Coronary calcium score improves classification of coronary heart disease risk in the elderly: the Rotterdam study. J Am Coll Cardiol 2010;56:1407-1414.

11 Kälsch H, Lehmann N, Möhlenkamp S, Hammer C, Mahabadi AA, Moebus S, Schmermund A, Stang A, Bauer M, Jöckel KH, Erbel R; Investigator Group of the Heinz Nixdorf Recall Study: Prevalence of thoracic aortic calcification and its relationship to cardiovascular risk factors and coronary calcification in an unselected population-based cohort: the Heinz Nixdorf Recall Study. Int J Cardiovasc Imaging 2013;29:207-216.

12 Rennenberg RJ, Schurgers LJ, Kroon AA, Stehouwer CD: Arterial calcifications. J Cell Mol Med 2010;14:22032210.

13 Jayalath RW, Mangan SH, Golledge J: Aortic calcification. Eur J Vasc Endovasc Surg 2005;30:476-488.

14 Nafakhi H, Al-Nafakh HA, Al-Mosawi AA, Algaraty F: Correlations between aortic root calcification and coronary artery atherosclerotic markers assessed using multidetector computed tomography. Acad Radiol 2015;22:357-362.

15 Erbel R, Möhlenkamp S, Kerkhoff G, Budde T, Schmermund A: Non-invasive screening for coronary artery disease: calcium scoring. Heart 2007;93:1620-1629.

16 Schmermund A, Mohlenkamp S, Baumgart D, Baumgart D, Kriener P, Pump H, Grönemeyer D, Seibel R, Erbel R: Usefulness of topography of coronary calcium by electron-beam computed tomography in predicting the natural history of coronary atherosclerosis. Am J Cardiol 2000;86:127-132.

17 Hoeg JM, Feuerstein IM, Tucker EE: Detection and quantitation of calcific atherosclerosis by ultrafast computed tomography in children and young adults with homozygous familial hypercholesterolemia. Arterioscler Thromb 1994;14:1066-1074.

18 Alnafakh H, Nafakhi H, Al-Jiboori M, Almosawi A, Tawfeq R: Aortic root calcification and cardiac risk factors in patients with coronary calcium score greater than zero using multi-detector computed tomography. Artery Res 2015;10:27-31. 